\title{
UN CRUCIFICADO DE IGNACIO DE RIES EN POTOSÍ
}

\author{
A CRUCIFIED OF IGNACIO \\ DE RIES IN POTOSÍ
}

\author{
RAFAel Ramos Sosa \\ Universidad de Sevilla, España \\ rabel@us.es
}

\begin{abstract}
Se da a conocer una pintura de Ignacio de Ries representando a un Cristo muerto en la cruz, firmada y fechada en 1646, localizada en el monasterio de santa Teresa de Potosí.

Palabras clave: Ignacio de Ries, Zurbarán, pintura, XVII, crucificado.

There is disclosed a painting of Ignacio de Ries representing a dead Christ on the cross, dated 1646 and located in the monastery of St. Teresa of Potosí.

Key words: Ignacio de Ries, Zurbarán, painting, XVII, crucified.
\end{abstract}

El conocimiento de Zurbarán y su obra siguen deparado continuados estudios e investigaciones que acreditan al maestro extremeño como un venero jugoso y profundo de recursos plásticos y honduras icónicas. La veta figurativa zurbaranesca desbordó en una amplia producción personal, así como la de su taller, discípulos, seguidores e imitadores. Buena parte de esa proyección llegó a Hispanoamérica, recibiendo y recreando, sobre todo su nervio espiritual, con declinaciones piadosas envueltas en el claroscurismo como técnica artística.

Las pesquisas de las últimas décadas han discurrido -entre otros aspectos- por la dificultosa labor de dirimir la pintura del maestro y la del fructífero obrador con discípulos y seguidores, además de localizar las piezas maestras desaparecidas. En esta línea se han decantado obras de Francisco y Miguel Polanco, Sebastián López de Arteaga, Juan Zurbarán, Ignacio de Ries, Bernabé de Ayala, recientemente el 
maestro de Besançon y otros ${ }^{1}$. Precisamente en estas breves páginas se redescubre una obra firmada y fechada de Ignacio de Ries (Sevilla, 1616- c.1665?), el discípulo más valorado y conocido de todos hasta ahora, ya que cuenta con una monografía ${ }^{2}$.

El investigador boliviano Mario Chacón dio a conocer en su libro publicado en la Sevilla de 1973, una pintura de un crucificado en las carmelitas de Potosí. Sacó a la luz la fotografía en blanco y negro, apuntando que estaba firmada por Ignacio de "Ríos" en 1646. Aclaraba que el lienzo se encontraba a gran altura, poco accesible y difícil lectura; además como puede apreciarse en la fotografía de entonces, con poca luz y suciedad, de ahí la equivocación ${ }^{3}$ (Figura 1).

Este lienzo puede verse con toda facilidad, tras la restauración y cambio de lugar, en el museo del monasterio de santa Teresa en Potosí ${ }^{4}$. Con la limpieza del lienzo y mejores condiciones de visión se observa una pintura de calidad con unas medidas de 2,24 x 1,56 m. Consta en la tela una cédula de papel pintada en el ángulo inferior derecho, a modo de trampantojo, con la siguiente firma: "ygnaçio De Ries fae, $S e^{a}, a^{o} 1646$ " (Figura 4). Así pues aquí se renueva aquel esfuerzo de Mario Chacón por desvelar el rico patrimonio de su tierra natal y las evidentes relaciones con el arte hispalense, tanto en pintura como en escultura ${ }^{5}$.

Tan importante óleo enriquece el catálogo de Ries en el que hasta ahora no constaba la iconografía del crucificado, ejercicio plástico e interpretativo al que todo artista de la época debía enfrentarse. La pintura manifiesta claramente los modelos y lecciones aprendidos en la casa de su mentor, ejecutado cuando ya se había establecido por su cuenta. El tipo físico de Jesús responde al conocido en la Alegoría del Árbol de la Vida y el Bautismo de la catedral de Segovia, aunque aquí gana en dignidad, hondura y convicción. Sobre un tenebroso fondo planta el

${ }^{1}$ DELENDA, Odile: Zurbarán, catálogo razonado y crítico. Madrid, 2009; el segundo volumen está dedicado al obrador y discípulos más destacados, pp. 286-291; VALDIVIESO, Enrique: Zurbarán, IV Centenario. Sevilla, 1998. CANO RIVERO, Ignacio: Francisco de Zurbarán (1598-1664). Bruselas, 2014. DELENDA, O. y BOROBIA, Mar, Zurbarán una nueva mirada, Madrid, 2015. Otras investigaciones de interpretación en GÓMEZ PIÑOL, Emilio: "El velo de la Verónica en la obra de Zurbarán", en Temas de Estética y Arte, XX, 2006, pp. 107-143.

${ }^{2}$ NAVARRETE PRIETO, Benito: Ignacio de Ries, Madrid, 2001.

${ }^{3}$ CHACÓN TORRES, Mario: Arte virreinal en Potosí. Sevilla, 1973, p. 107, fig. 29.

${ }^{4}$ El proyecto de restauración del conjunto arquitectónico y su patrimonio fue impulsado por la madre María del Amor, carmelita española de Utrera; gracias a su amabilidad pude recorrer las estancias y reparar en el lienzo, durante una larga estancia de investigación en Lima y Potosí en el 2004.

${ }^{5}$ RAMOS SOSA, Rafael: "Aportación a la obra del escultor Gaspar de la Cueva en Bolivia", en Manierismo y transición al Barroco. La Paz, 2005, pp. 67-76; y "Concurso de artes y letras', Aspectos artísticos del siglo de oro en Charcas", en Anuario de Estudios Bolivianos, 14, 2008, pp. 397-416. 
cuerpo escultórico de Cristo iluminado, sujeto por tres clavos a la cruz arbórea y cepillada, muerto y ligeramente descolgado, su cabeza se inclina a la izquierda sin ocultar al espectador el rostro sereno y grave, en el que la sangre apenas mancha la frente clavada de espinas. Una composición frontal con las piernas en disposición recta y leve giro del torso a la derecha. En definitiva mostrando la tensión del decoro religioso vigente en el primer tercio del seiscientos hispalense.

No muestra la boca entreabierta como sería de esperar, y resulta muy particular su tratamiento formal, modelando un grueso bulbo del labio superior sobre la carnosidad del inferior (Figura 2). Grafismo que puede verse también en su maestro pero en el que Ries acentúa el claroscurismo, evidente en el rey David del Prado y la Reina de los Cielos en la antigua colección Central-Hispano.

Constituye un detalle significativo el resplandor o nimbo luminoso sobre el casquete craneal coronado de espinas. Ese halo no aparece en Zurbarán y sus réplicas, pudiera verse como recurso iconográfico para acentuar la divinidad del ajusticiado $^{6}$. Ries opta por una interpretación serena del Dios-hombre, sin los dramatismos de la expiración en otros discípulos, ni el sobrecogedor aliento del maestro. En esta misma línea, la sangre cae en escasos hilillos desde la cabeza y el costado hasta llegar temerosamente al sudario (Figura 3). El habitual recurso plástico de infinitos tonos blancos remite al modelo del crucificado de san Pablo (1627) sin sus excelencias táctiles, pero anuda el paño con un cordón en pliegues más abullonados, como el ejemplar del museo sevillano (c.1635), distinguiéndose también por la caída lateral en movimiento ondulante.

Zurbarán y su taller cultivaron especialmente la representación estática del crucificado con cuatro clavos sobre subpedáneum. En cambio Ries se decantó -en esta única versión conocida- por los tres hierros y sin pedestal añadido, evocando tal vez el Cristo que mostraba san Buenaventura a santo Tomás de Aquino (1629). Igualmente, el titulus con la inscripción en los tres idiomas no es la habitual tablilla rectangular rígida, sino el folio flexible y con dobleces.

Sería la primera obra conocida con seguridad del pintor en la que vemos como sigue a su maestro en el modo de componer la figura, llenando todo el lienzo, de extremo a extremo, sobre fondo oscuro. Pero también hay diferencias al proyectar más luz sobre el cuerpo y rostro, modelando las formas con un claroscurismo mucho menor. Tal vez pudiera apuntar hacia cualidades de la posterior evolución plástica, donde luz, color y movimiento pujan en las creaciones de Murillo.

Por el momento desconocemos el cauce por el que llegaría este óleo hasta el cerro de plata andino. La fundación del monasterio fue en 1684, por lo que habría

${ }^{6}$ Aparece igual en el Cristo camino del Calvario de colección francesa, cfr. NAVARRETE, Benito: op. cit., p, 105, aunque la fotografía en blanco y negro recoge la pintura en mal estado. 
que pensar en una posterior donación de algún benefactor, o tal vez la dote de una novicia procedente de familias criollas en la antigua audiencia de Charcas.

Aquí tenemos un ejemplo de esa circulación de imágenes y mercado artístico americano tan demandado en el horizonte de las investigaciones actuales. Ocasión habrá de rememorar aquellas décadas, e invitar a dialogar al profesor con sus discípulos sobre un asunto como el desnudo artístico y su representación religiosa. Oír con la mirada la opinión de Sebastián López de Arteaga en las versiones de México, Ries en Sevilla y tantos otros, en las réplicas demandadas por entendidos, devotos o coleccionistas, junto a las conmovedoras lecciones y magisterio del crucificado de Chicago o las del museo hispalense ${ }^{7}$. Aunque los seguidores no alcancen al maestro lo iluminan con la modesta admiración de sus ojos, "ayudarán otra vez" a valorarlo más y apreciar la dilatada estela abierta en su tiempo.

Fecha de recepción: 20 de julio de 2014

Fecha de aceptación: 28 de noviembre de 2014

${ }^{7}$ Arteaga llegó a Nueva España hacia 1640 y habitualmente es considerado discípulo o seguidor, cfr. MOYSSÉN, Xavier: "Sebastián de Arteaga", en Anales del Instituto de Investigaciones Estéticas, 59, 1988, pp. 17-34. 


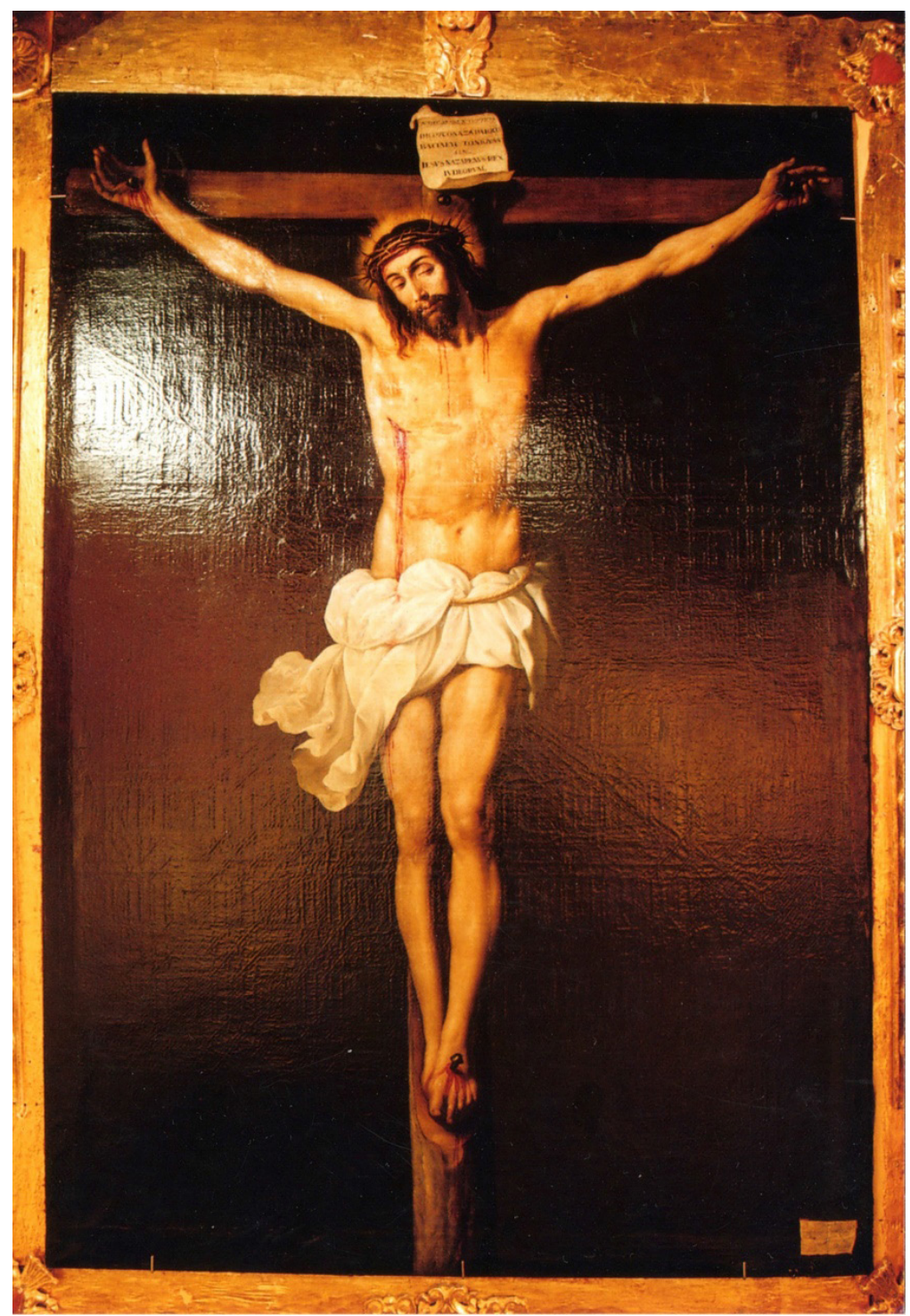

Figura 1. Crucificado, Ignacio de Ries, 1646, monasterio de santa Teresa, Potosí. 


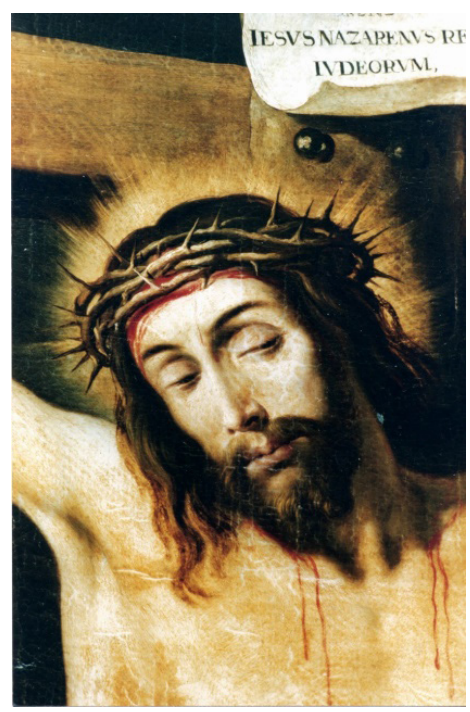

Figura 2. Crucificado, detalle del rostro, Ignacio de Ries, Potosí.

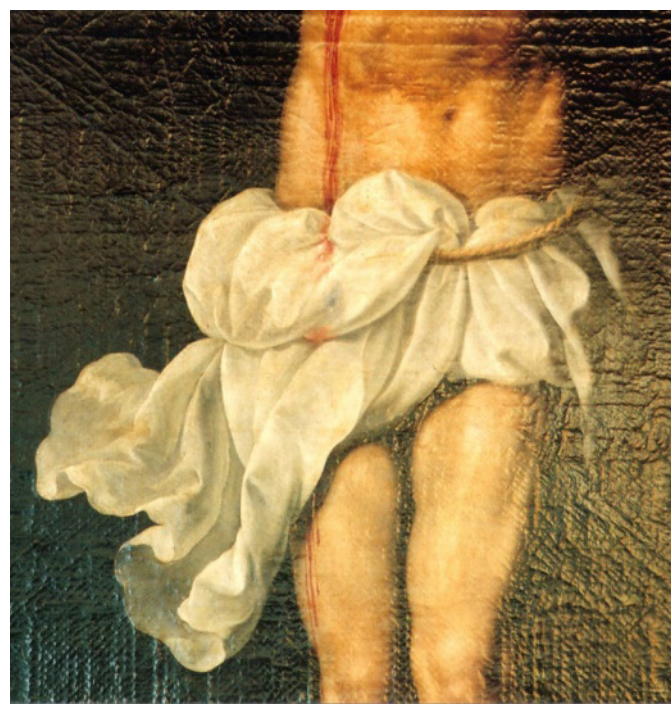

Figura 3. Crucificado, detalle del paño de pureza, Ignacio de Ries, Potosí.

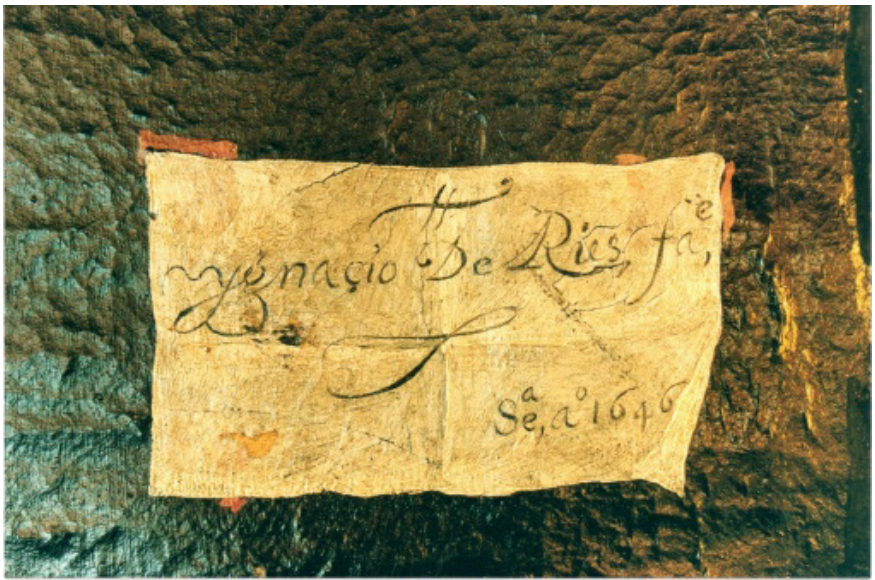

Figura 4. Crucificado, detalle de cédula con firma y fecha, Ignacio de Ries, 1646. 